\title{
Novelty-induced arousal enhances memory for cued classical fear conditioning: Interactions between peripheral adrenergic and brainstem glutamatergic systems
}

\author{
Stanley O. King II and Cedric L. Williams ${ }^{1}$ \\ Department of Psychology, Neuroscience and Behavior Graduate Program, University of Virginia, Charlottesville, \\ Virginia 22904-4400, USA
}

\begin{abstract}
Exposure to novel contexts produce heightened states of arousal and biochemical changes in the brain to consolidate memory. However, processes permitting simple exposure to unfamiliar contexts to elevate sympathetic output and to improve memory are poorly understood. This shortcoming was addressed by examining how novelty-induced changes in peripheral and/or central arousal modulates memory for Pavlovian fear conditioning. Male rats were either exposed to the conditioning chamber for 5 -min or given no exposure $24 \mathrm{~h}$ before conditioning with five tone-shock $(0.35 \mathrm{~mA})$ pairings. Retention was assessed $48 \mathrm{~h}$ later in a different context. Non-pre-exposed animals exhibited significantly greater freezing during conditioned stimulus (CS) presentations than did pre-exposed animals $(P<0.05)$. The improvement in retention produced by novelty was attenuated by pretraining a blockade of peripheral $\beta$-adrenergic receptors with sotalol ( $6 \mathrm{mg} / \mathrm{kg}$, i.p.). Study 2 revealed that novelty-induced increases in peripheral autonomic output are conveyed to the brain by visceral afferents that synapse upon brainstem neurons in the nucleus tractus solitarius (NTS). Blocking AMPA receptor activity in the NTS with CNQX $(1.0 \mu \mathrm{g})$ significantly reduced freezing to the CS in non-pre-exposed animals $(P<0.01)$. Study 3 showed that elevating epinephrine levels in habituated animals influences learning through mechanisms similar to those produced by novelty-induced arousal. Pre-exposed animals given epinephrine $(0.1 \mathrm{mg} / \mathrm{kg})$ froze significantly more than saline controls $(P<0.01)$, and this effect was attenuated by intra-NTS infusion of CNQX. The findings demonstrate that novelty-induced arousal or increasing sympathetic activity with epinephrine in preexposed animals enhances memory through adrenergic mechanisms initiated in the periphery and transmitted centrally via the vagus/NTS complex.
\end{abstract}

An emerging number of findings reveal that novelty associated with exposure to unknown contexts or unfamiliar arrays of stimuli initiates both cellular and physiological changes that are adaptive in encoding attributes of new events into memory. The adaptive value of novelty exposure in up-regulating processes underlying memory and synaptic plasticity are observed as early as $3 \mathrm{wk}$ postnatal (Tang and Reeb 2004) and documented in elderly rats tested beyond 22 mo of age (Sierra-Mercado et al. 2008). The impact of novel stimuli in strengthening new representations may be related in part to their capacity to initiate a cascade of biochemical changes necessary for long-term memory formation.

The development of new associations following learning is mediated in part by increased phosphorylation of cAMP response element binding protein (CREB) and subsequent CRE-mediated gene expression to bind individual components of new events into a collective memory trace (Alberini 2009). CREB phosphorylation is up-regulated within the hippocampus following placement in a novel environment, and this important step in memory formation persists beyond an hour following the novel experience but remains unchanged in subjects exposed to a familiar context (Kinney and Routtenberg 1993; Viola et al. 2000; Izquierdo et al. 2001). Exposing animals to a novel context induces greater levels of the immediate early genes c-fos and c-jun in the amygdala and

\footnotetext{
'Corresponding author.
}

E-mail clw3b@virginia.edu; fax (434) 982-4785.

Article is online at http://www.learnmem.org/cgi/doi/10.1101//m.1513109. hippocampus, but these changes are not observed in groups that are reintroduced to, or allowed to, explore a familiar context (Papa et al. 1993; Zhu et al. 1997; Sheth et al. 2008). The enduring effects of brief episodes of novelty exposure on arousal and attentive processes are also sufficient to enhance retrieval for remote memory (Izquierdo et al. 2000, 2003) and to strengthen memory under mild training conditions that normally yield poor retention performance. Moncada and Viola (2007) showed that inhibitory avoidance training with a suboptimal footshock results in weak or no memory in controls tested $24 \mathrm{~h}$ later. However, subjects exposed to an unfamiliar context either prior to or even immediately after training with the weak footshock exhibited significantly better retention relative to controls when memory was assessed $24 \mathrm{~h}$ later.

Placement in a novel environment prior to the induction of long-term potentiation (LTP) with a weak ineffective tetanization facilitates the progression of early LTP to late LTP, which requires de novo protein synthesis, and this form of exploration prolongs LTP maintenance for a period ranging from 8 to $24 \mathrm{~h}$ ( $\mathrm{Li}$ et al. 2003; Straube et al. 2003a,b). These effects are not observed if LTP is initiated in training contexts rendered familiar as a consequence of prolonged habituation. Interestingly, blockade of noradrenergic receptors with intracerebroventricular infusion of propranolol prior to placement in an unfamiliar context prevents noveltyinduced enhancement of LTP, suggesting a role of norepinephrine in mediating novelty effects within the brain (Straube et al. 2003a). An involvement of this neurotransmitter is also suggested by findings showing locus coeruleus (LC) neurons that supply norepinephrine to 
forebrain and limbic structures display phasic bursts of activity upon initial exposure to a novel environment, but increased discharge does not occur in rats returned to a familiar context (Vankov et al. 1995). Other findings, reporting that norepinephrine concentrations in the frontal cortex and hypothalamus are significantly elevated following exposure to a novel illuminated environment or training context containing an unfamiliar rat (McQuade et al. 1999), provide more direct evidence that norepinephrine mediates central changes in response to novelty exposure. These collective findings demonstrate that novelty induced by subtle exposure to an unfamiliar context influences a number of neurochemical and synaptic changes that are required for new experiences to be encoded effectively into longterm memory.

The consequences of brief exposure to unfamiliar environments are not limited to the well-documented biochemical changes observed in the brain. Autonomic indices of sympathetic activity, including skin conductance, cardiac output, and circulating concentrations of the adrenal hormones corticosterone and epinephrine, are all elevated by presenting humans or animals with novel stimuli or after allowing free exploration in an unfamiliar environment (De Boer et al. 1990; Bradley et al. 1993; Handa et al. 1994; Gerra et al. 1996; Codispoti et al. 2006). These findings reveal important parallels between the class of physiological changes that emerge as a direct result of exposure to novel environment and those elicited by emotionally arousing events. Although both conditions induce changes that modulate peripheral visceral activity and brain limbic output to encode new events into memory, the mechanism by which novelty-induced peripheral and/or central arousal may influence memory formation is not completely understood.

Several lines of evidence suggest that the arousal-related hormone epinephrine plays complementary roles in both processes. For example, systemic injection of epinephrine in a range of doses that improve memory in laboratory rats (Williams and McGaugh 1993; Clayton and Williams 2000; Nordby et al. 2006; Dornelles et al. 2007) increases the firing rate of noradrenergic LC neurons (Holdefer and Jensen 1987) that display high levels of discharge following exposure to novel contexts (Vankov et al. 1995). As with novelty, epinephrine administration facilitates LTP (Korol and Gold 2008) and reverses deficits in retention for contextual fear conditioning displayed by mice with the transcription factor CREB genetically disrupted (Frankland et al. 2004). Presentation of novel visual slides to humans improves memory (Fenker et al. 2008) and initiates epinephrine secretion from the adrenals (Gerra et al. 1996), and this change in arousal is sufficient to improve later retention performance (Cahill et al. 1994) comparable to that produced by direct administration of this hormone (Cahill and Alkire 2003). The arousal-induced enhancement in human memory with novel visual slides (Strange and Dolan 2004) and the novelty-induced facilitation of LTP discussed above (Li et al. 2003; Straube et al. 2003a,b) are both attenuated by blocking noradrenergic receptor transmission with the $\beta$-adrenergic receptor antagonist propranolol. These types of findings provide the foundation for determining whether novelty-induced arousal and the subsequent physiological changes that assist in encoding features of new experiences into memory are mediated through interactions involving peripheral hormonal systems that influence noradrenergic activity in the brain.

If brief periods of novelty exposure induce arousal through this mechanism, then it is plausible that one means by which arousal impacts the strength that emotional episodes are stored into memory is by activating neural pathways that transmit the sympathomimetic actions of epinephrine mediated in the periphery to brain systems that influence norepinephrine output in the CNS. Peripheral branches of the vagus serve a key role in this process as ascending fibers of the vagus are densely embedded with $\beta$-adrenergic receptors that bind epinephrine (Schreurs et al. 1986; Lawrence et al. 1995), and peripheral endings of the vagus innervate sensory organs that are highly responsive to sympathetic arousal produced by epinephrine release or novelty, including the heart, liver, stomach, and lungs (Shapiro and Miselis 1985; Coupland et al. 1989; Paton 1998a, b). Moreover, electrical stimulation of ascending vagal fibers produce significant burst firing in LC neurons (Groves et al. 2005; Dorr and Debonnel 2006) and lead to long-lasting elevations in norepinephrine concentrations collected from the amygdala (Hassert et al. 2004) and hippocampus (Miyashita and Williams 2002).

Information regarding heightened activity in peripheral sensory organs is transmitted by ascending vagal fibers to a specific cluster of cells in the brainstem known as the nucleus of the solitary tract (NTS) (Kalia and Sullivan 1982; Sumal et al. 1983). In response to these changes, NTS neurons influence central noradrenergic activity through direct synapses on LC neurons (Van Bockstaele et al. 1999) that not only become active in the presence of novel stimuli (Vankov et al. 1995) but also modulate norepinephrine release in structures that play important roles in encoding new experiences into long-term memory such as medial prefrontal cortex, hippocampus, and amygdala (Ricardo and Koh 1978; Loughlin et al. 1986; Florin-Lechner et al. 1996).

If novelty-induced arousal increases epinephrine secretion, then it is plausible that one means by which arousal impacts the strength in which emotional episodes are stored into long-term memory is by activating this vagal/NTS pathway. The present study tests this hypothesis by using the "familiarity" versus "novelty" of the training context as a manipulation to increase physiological arousal prior to learning and examine whether storage of emotionally laden memories are influenced by peripheral adrenergic activation. Pavlovian fear conditioning is frequently used to understand the neural circuits involved in forming memories for emotionally arousing experiences (Kim and Jung 2006), although the effects of manipulating physiological arousal during the formation of fear conditioned memory has not been widely explored.

Given this shortcoming, these studies examined how changes in peripheral physiological activity are transmitted by the vagus/NTS complex to reveal the mechanisms by which novelty-induced arousal influences memory for fear conditioning. The objective of experiment 1 was to assess the contribution of peripheral adrenergic activity in mediating novelty-induced arousal and its subsequent effects on mnemonic processing. In this study, novelty was induced in separate groups by withholding habituation and waiting until the day of conditioning to introduce subjects to the training context for the first time. The consequences of blocking peripheral adrenergic receptors prior to Pavlovian conditioning was examined in groups in which the training context represented novelty exposure and compared to groups that were familiarized with the fear conditioning chamber through previous habituation. Study 2 examined whether the pathway between peripheral vagal afferents and brainstem nuclei in the NTS mediate the mnemonic consequences of noveltyinduced increases in sympathetic activity during fear conditioning. The amino acid glutamate is the primary transmitter mediating synaptic communication between vagal afferents and NTS neurons since vagal terminals contain glutamate (Sykes et al. 1997) and glutamate receptors are localized on NTS dendrites (Aicher et al. 1999, 2002). In addition, intra-NTS infusion of the AMPA glutamatergic receptor antagonists CNQX (6-cyano-7-nitroquinoxaline-2,3-dione) suppresses excitatory burst firing in NTS neurons activated by stimulating the vagus nerve (Granata and Reis 1983a; Andresen and Yang 1990) with a range of currents that increase LC discharge (Groves et al. 2005; Dorr and Debonnel 
2006) or potentiates norepinephrine release in the amygdala or hippocampus (Miyashita and Williams 2002; Hassert et al. 2004). To this end, the AMPA receptor antagonist CNQX was used to block postsynaptic glutamate receptors in the region of the NTS that receives input from vagal terminals. The location of cannulae and injection needle tips aimed at the NTS is depicted in Figure 1.

Study 3 investigated whether the poor memory exhibited by habituated control groups familiar with the training context could be enhanced by increasing peripheral activity after Pavlovian conditioning with systemic injection of epinephrine. This study also determined if glutamatergic transmission between vagal afferents and NTS neurons plays a critical role in meditating the direct changes on memory produced by elevated concentrations of epinephrine. Findings emerging from these studies reveal that arousal induced by environmental novelty or by exogenously amplifying sympathetic activity with epinephrine enhances Pavlovian fear conditioned memory through adrenergic mechanisms initiated in the periphery and transmitted centrally via the vagus/ NTS complex.

\section{Results}

\section{Experiment 1}

\section{Fear conditioned training}

This study determined if the improvement in memory produced by novelty exposure and subsequent Pavlovian fear conditioning training is mediated by activating peripheral adrenergic systems. It was hypothesized that the secretion of epinephrine would be a necessary component for novelty-induced arousal to improve memory. This hypothesis was examined by using the peripheral $\beta$-adrenergic receptor antagonist sotalol to block epinephrine binding to peripheral $\beta$-adrenergic receptors in rats exposed to the novel conditioning context.

A two-way factorial ANOVA on the mean percentage of freezing, exhibited to the final presentation of the conditioned stimulus (CS; tone) during acquisition with five CS-unconditioned stimulus (US) pairings, revealed no statistical differences between the treatment groups in their capacity to learn that the CS tone is a reliable predicator of the US footshock and elicits freezing, $F_{(1,20)}=$ $1.48, P=$ NS (pre-exposed/saline $88.38 \pm 7.3$, pre-exposed/sotalol $90.68 \pm 4.0$, non-pre-exposed/saline $97.28 \pm 2.0$, non-pre-exposed/ sotalol $84.16 \pm 6.9)$.

\section{Retention test}

A two-way ANOVA indicated a significant overall effect of treatment on the mean percentage of freezing exhibited during three presentations of the CS during retention testing in a completely different Pavlovian chamber $\left(F_{(1,20)}=21.26\right.$, $P<0.01$; Fig. 2A). Post-hoc tests revealed that non-pre-exposed animals exhibited significantly more freezing during CS presentations than did the habituated animals that were pre-exposed to the conditioning chamber $24 \mathrm{~h}$ prior to training $(P<0.05)$. Additionally, non-pre-exposed animals, administered the peripherally acting $\beta$-adrenergic receptor antagonist sotalol, exhibited significantly less overall freezing during the three CS presentations relative to non-pre-exposed animals given saline injections $(P<0.01)$. Toneby-tone analysis of freezing with factorial ANOVAs indicated that non-pre-exposed subjects displayed a significantly higher level of freezing to each individual tone presentation relative to all other groups (see Fig. 2B). Thus, the reported arousal associated with placing organisms in a novel context (De Boer et al. 1990; Handa et al. 1994) contributes to enhanced encoding of emotional learning. Moreover, the beneficial consequences of arousal on memory for CS-US pairings are contingent upon activation of peripheral hormonal systems that bind to $\beta$-adrenergic receptors.

\section{Experiment 2}

\section{Fear conditioned training}

The second study examined whether physiological changes induced in the periphery by exposure to a novel environment affect memory for fear conditioning by activating neurons in the NTS. It was predicted that novelty-induced arousal reflected by autonomic activation enhances memory via epinephrine binding to $\beta$-adrenergic receptors along ascending fibers of the vagus nerve. Increased transmission along the vagus would in turn excite neurons in the NTS that are innervated by vagal terminals that release glutamate. Given this assumption, blocking AMPA receptor activity associated with glutamate release in the NTS immediately post-conditioning for non-pre-exposed animals should attenuate the memory improvement from novelty-induced arousal. The initial findings from this study indicated no differences between the treatment groups in their capacity to learn the CS-US associations during training. All groups demonstrated comparable levels of freezing to the final CS presentation during conditioning, $F_{(1,25)}=0.670, P=$ ns (pre-exposed/PBS $92.0 \pm 5.0$, pre-exposed/ CNQX $86.1 \pm 5.2$, non-pre-exposed/PBS $96.0 \pm 2.2$, non-preexposed/CNQX $96.3 \pm 1.1)$.

\section{Retention test}

A two-way ANOVA revealed significant overall effects on mean percentage of freezing to the three CSs presented during retention testing, $F_{(1,25)}=9.60, P<0.01$. As with experiment 1 , non-preexposed animals given vehicle injections into the NTS froze for a significantly higher percentage of time when the CS was presented compared with pre-exposed controls and pre-exposed animals administered CNQX into the NTS $(P<0.01$; Fig. 3A). Post-hoc results indicated that a bilateral infusion of CNQX into the NTS significantly reduced the high percentage of freezing observed in non-pre-exposed animals to levels that were comparable to that of

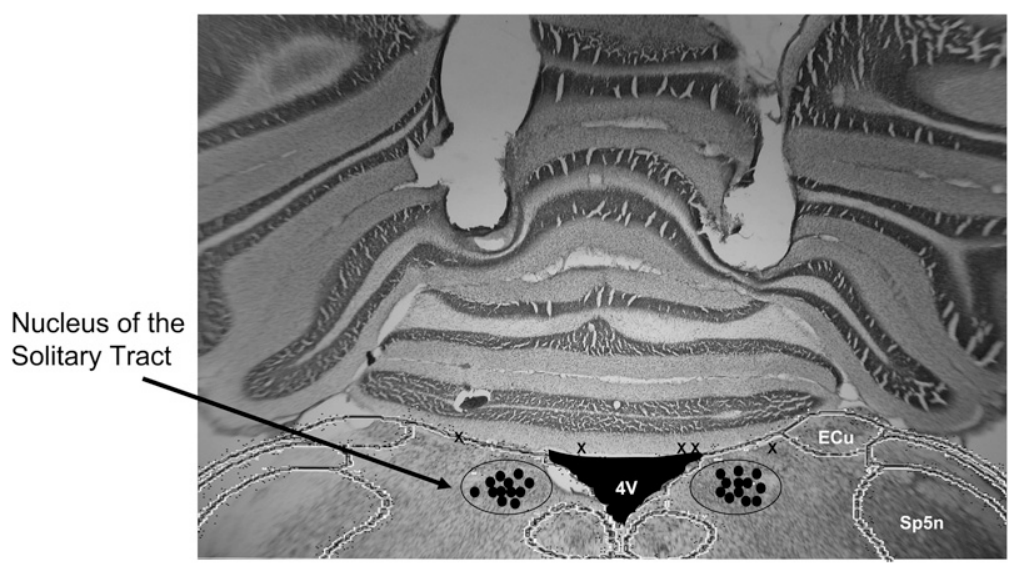

Bregma $-13.3 \mathrm{~mm}$

Figure 1. Location of needle tip placements in the nucleus of the solitary tract (NTS) overlaid onto a representative photomicrograph from animals trained and tested in experiments 2 and 3 . (•) Indicates correct cannula and needle tip placements within the caudal NTS; X, incorrect cannula and needle tip placements; 4V, fourth ventricle; ECu, external cuneate nucleus; and Sp5n, spinal trigeminal nucleus. 
A

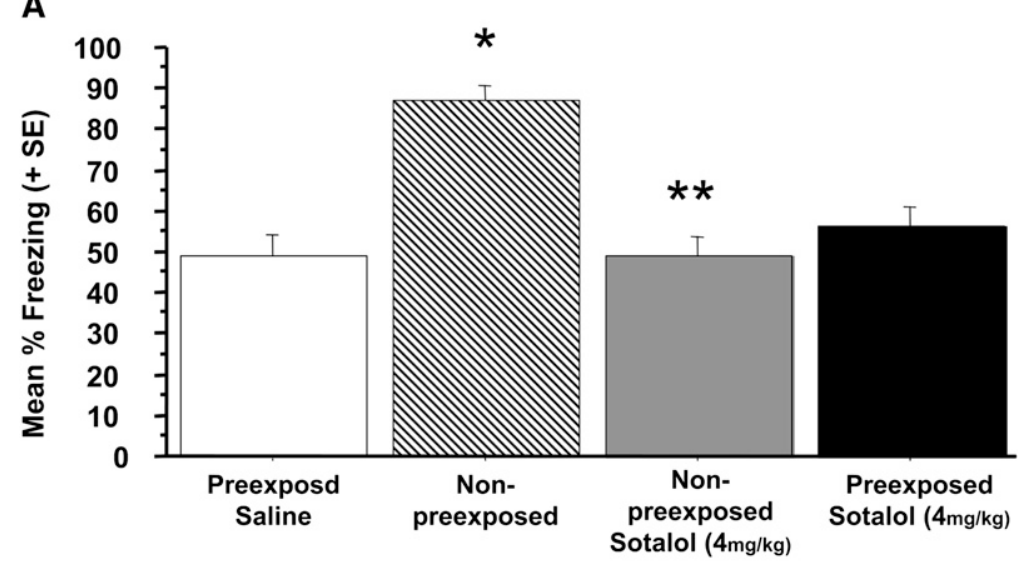

B

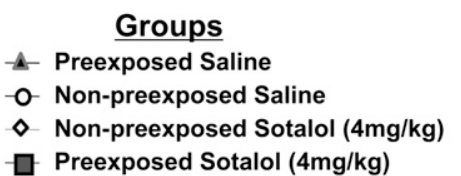

100

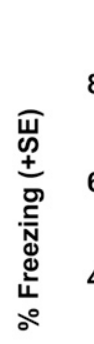

00
60
40
20

0

\author{
)
}

.

\section{.}

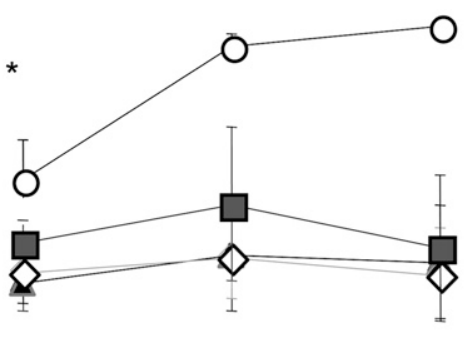

Figure 2. ( $A$ ) Groups: Peripheral $\beta$-adrenergic blockade with sotalol $(4 \mathrm{mg} / \mathrm{kg})$ impairs noveltyinduced memory enhancement. Non-pre-exposed animals given a systemic injection of saline before conditioning in a novel chamber exhibit a significantly greater percentage of freezing (i.e., 87\%) during presentations of the CS compared with all experimental groups $\left({ }^{*} P<0.05\right)$. Blocking $\beta$-adrenergic receptors in the periphery with sotalol prior to conditioning in the novel chamber significantly reduced the percentage of freezing (i.e., $49 \%$ ) elicited by presentation of the CS during retention testing $\left({ }^{* \star} P<\right.$ $0.01)$. Twenty-four animals were divided into the following treatment groups (pre-exposed-saline, $n=$ 6; non-pre-exposed-saline, $n=5$; non-pre-exposed sotalol, $n=8$; and pre-exposed sotalol, $n=5$ ). (B) Retention trials: Line graph depicting trial-by-trial freezing to CS tone presentations during retention testing. Non-pre-exposed animals treated with i.p. saline injections prior to conditioning in a novel chamber showed a significantly higher level of freezing than all other groups during the first CS presentation $\left({ }^{*} P<0.05\right)$. The percentage of freezing in this group during subsequent CS presentations was also significantly greater than each treatment group $\left({ }^{* *} P<0.01\right)$. Peripheral $\beta$-adrenergic blockade with sotalol $(4 \mathrm{mg} / \mathrm{kg}$ ) attenuated the impact of novelty-exposure on enhanced freezing to the CS tone.

pre-exposed controls $(P<0.01)$. Figure 3B shows the percentage of freezing during each of the three CS tone presentations. On only the first presentation of the CS, non-pre-exposed saline treated animals froze significantly more than non-pre-exposed CNQX treated animals $(P<0.02)$, but not the pre-exposed groups. The non-pre-exposed group froze significantly more than all groups during the second and third presentations of the CS $(P<0.01)$. These findings demonstrate that novelty-induced enhancement in memory for Pavlovian fear conditioning is attenuated by
Tone 3 blocking access to postsynaptic glutamate receptors in the NTS with bilateral infusions of the AMPA receptor antagonist CNQX.

\section{Experiment 3}

\section{Fear conditioned training}

The final study examined whether increasing circulating concentrations of epinephrine improves Pavlovian conditioning through mechanisms similar to those produced by novelty-induced arousal. If the two types of manipulations share similar pathways, then any changes in conditioning mediated by epinephrine should be attenuated by disrupting the same NTS mechanism shown to be critical for novelty-induced arousal to affect memory. This hypothesis was examined by infusing the AMPA receptor antagonist CNQX in the NTS $\sim 2$ min before systemic administration of epinephrine $(0.1 \mathrm{mg} / \mathrm{kg})$. Both treatments were given after conditioning with the five CS-US pairings. All pre-exposed treatment groups exhibited comparable percentages of freezing to the final presentation of the CS during conditioning, $F_{(1,26)}=$ 0.057, $P=$ NS (saline/PBS $94.6 \pm 3.1$, saline/CNQX $92.5 \pm 4.0$, epinephrine/ PBS $97.9 \pm 2.1$, epinephrine/CNQX 94.3 $\pm 4.0)$.

\section{Retention test}

A two-way ANOVA indicated a significant overall effect on the mean percentage of freezing demonstrated to three presentations of the CS during retention testing, $F_{(1,26)}=12.13, P<0.01$. Post-hoc tests revealed that pre-exposed animals given an intra-NTS infusion of PBS and a systemic injection of epinephrine exhibited a significantly higher percentage of freezing to the CS compared with all other treatment groups $(P<0.01)$. However, pre-exposed animals given the same systemic dose of epinephrine after bilateral infusions of CNQX into the NTS were indistinguishable from PBS injected controls ( $P=\mathrm{NS}$; Fig. 4A). Figure 4B shows the percentage of freezing during each of the three CS tone presentations. The epinephrine group $(0.1 \mathrm{mg} / \mathrm{kg})$ froze significantly more than did saline controls during the initial presentation of the CS $(P<0.05)$, but their percentage of freezing did not differ from that of the CNQX groups. However, during the second and third presentation of the CS, epinephrine-treated animals froze significantly more than all other treatment groups $(P<0.01)$. The epinephrine-induced enhancement in memory for tone-shock associations was attenuated by a CNQX blockade of AMPA receptors in the NTS as freezing levels in this group were not significantly different from saline controls. These findings suggest the vagus/NTS complex is a critical component of the mechanisms involved in conveying heightened states of physiological arousal 
A

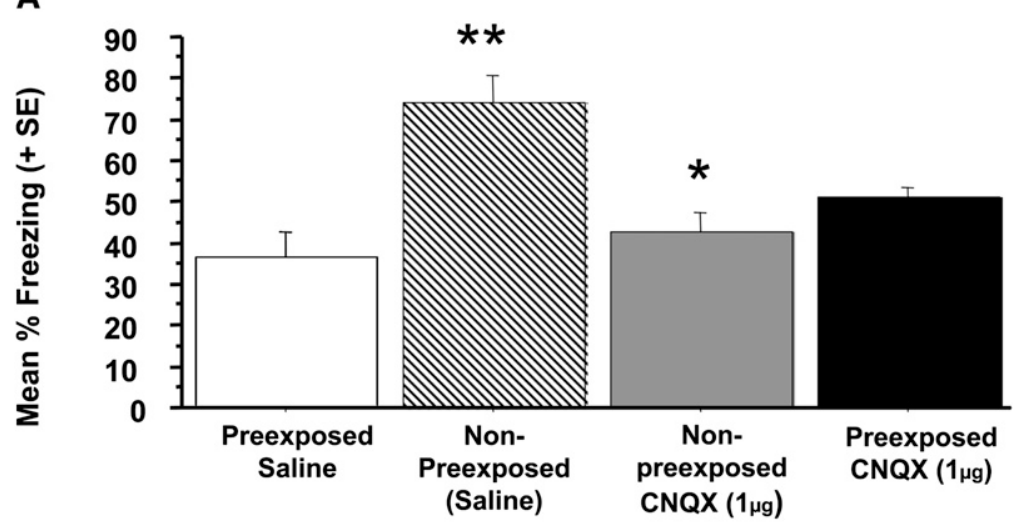

B

\section{Groups}

- Preexposed Saline

- - Non-preexposed Saline

$\diamond$ Non-preexposed CNQX $(1 \mu \mathrm{g})$

- Preexposed CNQX (1 $1 \mu \mathrm{g})$

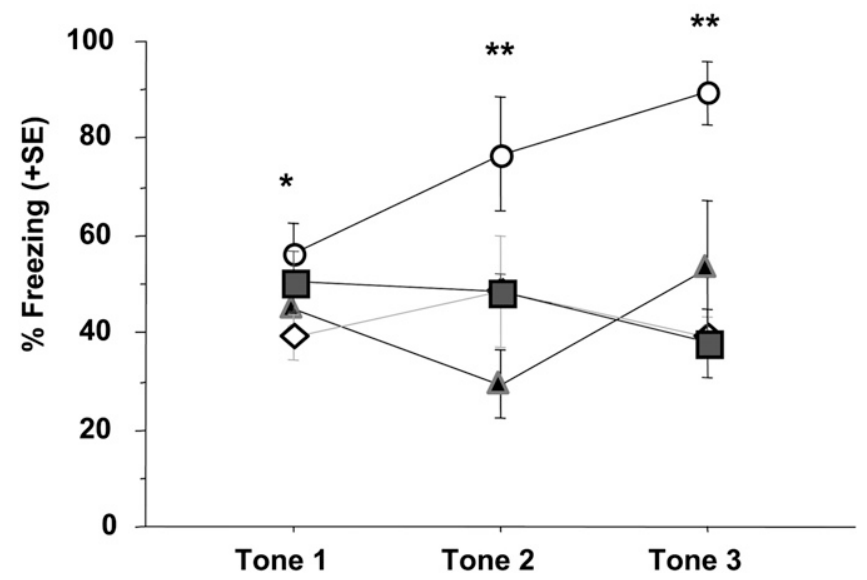

Figure 3. (A) Groups: CNQX $(1.0 \mu \mathrm{g})$ blockade of glutamatergic transmission in the nucleus of the solitary tract (NTS) attenuates novelty-induced memory enhancement. The non-pre-exposed group given vehicle into the NTS exhibited a significantly higher percentage of freezing than all experimental groups during three CS presentations given during a $48 \mathrm{~h}$ retention test $\left({ }^{* *} P<0.01\right)$. The enhancement in memory produced by novelty at the time of conditioning was attenuated by blocking AMPA receptors in the NTS with CNQX. The non-pre-exposed-CNQX group showed significantly poorer memory for the CS reflected in reduced freezing to the CS relative to the non-pre-exposed group given PBS into the NTS $\left({ }^{*} P<0.05\right)$. Twenty-nine subjects were divided into the following treatment groups (pre-exposed PBS, $n=8$; non-pre-exposed PBS, $n=8$; pre-exposed CNQX, $n=6$; and non-pre-exposed CNQX, $n=7)$. ( $(B)$ Retention trials: Line graph depicting trial-by-trial freezing to CS tone presentations during retention testing. Subjects in the non-pre-exposed saline group showed a significantly higher level of freezing than all other groups during the second and third presentation of the tone CS $(* * P<0.01)$. The high level of freezing exhibited by non-pre-exposed subjects was attenuated by blocking AMPA receptors in the NTS with CNQX.

produced by emotionally laden experiences to brain systems that encode and store memory for fear conditioning.

\section{Discussion}

These experiments examined whether the intensity of arousal induced by the novelty of a learning context influences memory for Pavlovian fear conditioning. Findings from the three experiments reveal that memory for tone-shock pairings is enhanced in groups conditioned in a completely novel context relative to groups that were previously exposed by habituation in the training context $24 \mathrm{~h}$ before fear conditioning. Study 1 also examined whether the beneficial actions of arousal produced by exposure to the novel training context involves activation of peripheral sympathetic hormones. To this end, sotalol was administered preconditioning to block peripheral $\beta$-adrenergic receptors that bind the arousal related hormone epinephrine. The higher percentage of freezing behavior observed in groups conditioned in a novel context was attenuated by blocking these receptors before conditioning with sotalol. The results from study 1 suggest that arousal-induced changes in memory produced by the novelty of a conditioning context involve secretion of adrenal hormones and subsequent actions of these hormones on peripheral $\beta$-adrenergic receptors.

The interpretation of this finding was extended in study 2 by determining whether the mnemonic consequences of novelty are mediated in part by activation of brainstem neurons that are responsive to arousal-induced fluctuations in peripheral hormonal and sympathetic output. The adrenal hormone epinephrine binds to $\beta$-adrenergic receptors along vagal nerve fibers (Lawrence et al. 1995) that ascend to the brainstem and synapse upon neurons in the NTS (Kalia and Sullivan 1982). Arousal-induced changes in adrenal hormonal secretion increase discharge along vagal afferent fibers (Miyashita and Williams 2006) that, in turn, excite NTS neurons by releasing glutamate from its terminals (Granata and Reis 1983b; Allchin et al. 1994). Study 2 assessed the functional significance of glutamate release from excited vagal afferents onto NTS neurons in mediating the effects of novelty on memory. Findings from this study demonstrated that increased freezing observed during the tone retention test in subjects trained in a novel conditioning chamber was attenuated by blocking AMPA receptors in the NTS with the selective glutamate receptor antagonist CNQX.

It is important to note that although the experimental conditions used to induce novelty in experiments 1 and 2 facilitate later retention of cue-shock associative learning, novelty exposure with more intense environmental stimuli has been observed to produce opposite effects on mnemonic processing. For example, placement in an unfamiliar context in conjunction with restraint, restraint plus intermittent tail shock, in the presence of a freely moving cat or in an elevated platform that is brightly illuminated, disrupts induction of LTP, primed burst potentiation, and memory for spatial learning (Diamond et al. 1990, 1994; Xu et al. 1997; Akirav and RichterLevin 1999; Diamond and Park 2000). The differences in memory and synaptic plasticity observed in these studies relative to those 
A

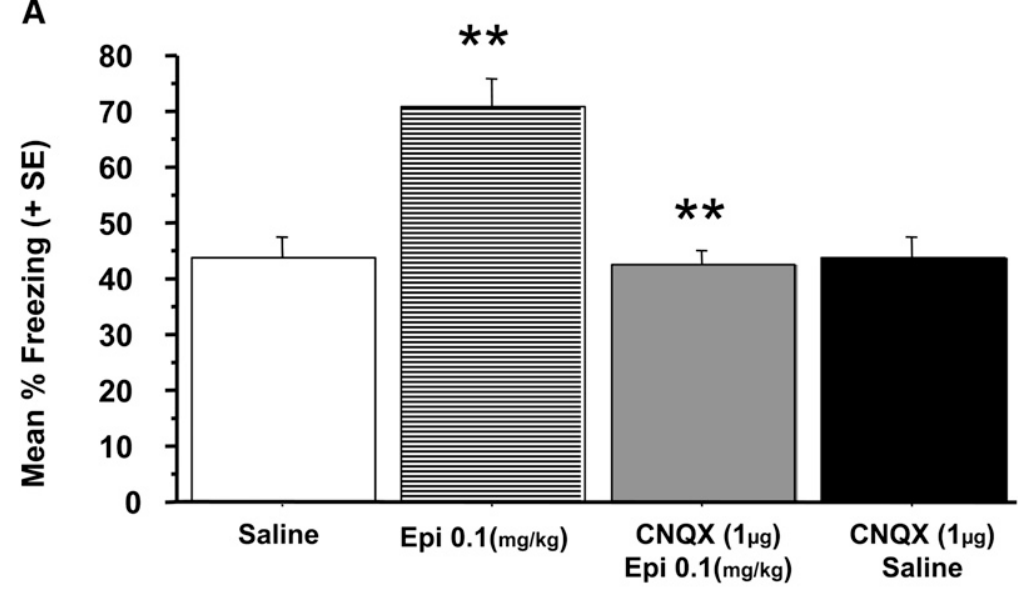

B
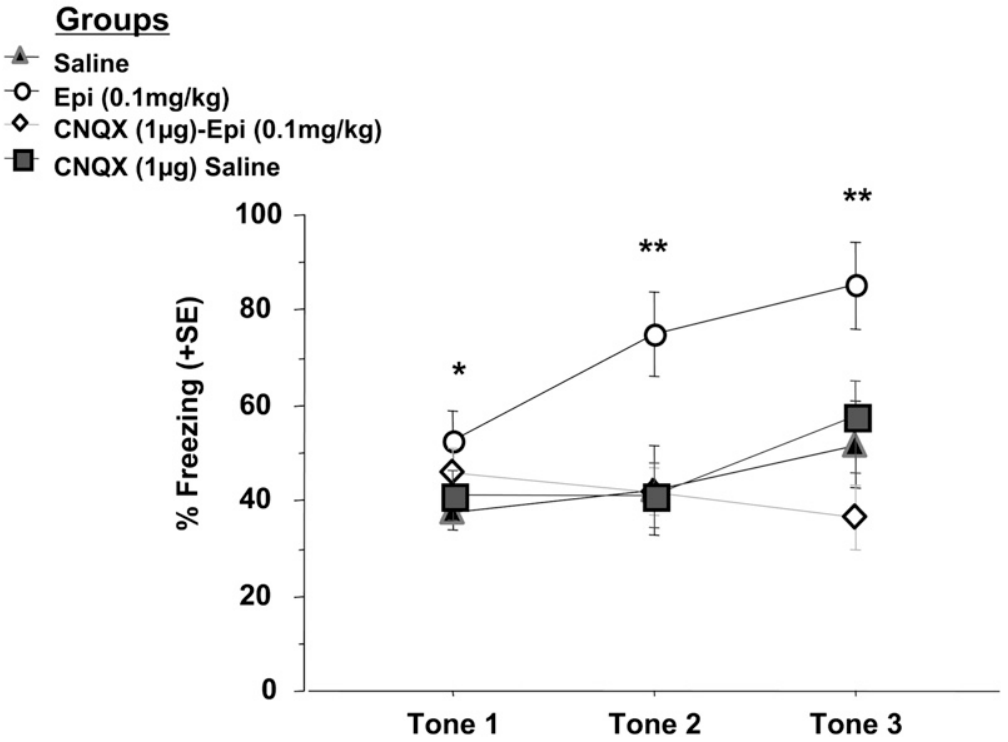

Figure 4. (A) Pre-exposed groups: Antagonizing AMPA receptors in the NTS attenuates epinephrineinduced facilitation in fear conditioning. The percentage of freezing exhibited by pre-exposed animals given a systemic injection of epinephrine $(0.1 \mathrm{mg} / \mathrm{kg})$ following learning (71\%) was significantly greater than saline-injected controls (44\%) during three presentations of the CS on a 48-h retention test (**P< $0.01)$. The memory enhancement produced by systemic epinephrine administration was significantly reduced when AMPA receptors were blocked in the NTS with CNQX $(1.0 \mu \mathrm{g})$ before arousal was increased with epinephrine $\left({ }^{* *} P<0.01\right)$. There were no differences in the percentage of freezing demonstrated by any pre-exposed groups given CNQX into the NTS from control animals given a systemic injection of saline. Thirty animals were divided into the following treatment groups (salinePBS, $n=9$; saline-CNQX, $n=6$; epinephrine-PBS, $n=10$; and epinephrine-CNQX, $n=5)$. (B) Retention trials: Line graph depicting trial-by-trial freezing to CS tone presentations during retention testing. The group given post-training epinephrine $(0.1 \mathrm{mg} / \mathrm{kg})$ exhibited a significantly higher level of freezing than all other groups during the second and third presentation of the tone CS $\left({ }^{* *} P<0.01\right)$. The epinephrineinduced enhancement in memory for tone-shock associative learning was blocked by antagonizing AMPA receptors in the NTS with CNQX $(1.0 \mu \mathrm{g})$. ${ }^{*} P<0.05$.

reporting memory enhancement by using brief periods of nonstressful novelty exposure (Kinney and Routtenberg 1993; Vankov et al. 1995; Izquierdo et al. 2000, 2001, 2003; Viola et al. 2000; Li et al. 2003; Straube et al. 2003a,b; Davis et al. 2004; Moncada and Viola 2007; Sierra-Mercado et al. 2008) may be related to the magnitude of arousal and subsequent levels of stress induced by the respective training conditions.
If, however, brief exposure to novel contexts creates a moderate level of arousal through secretion of adrenal hormones, then administration of epinephrine to habituated subjects should increase arousal to a level comparable to that produced by Pavlovian conditioning in a context that was completely new. This premise was tested in the final study by examining whether more intensive levels of fear-induced freezing are exhibited on a 48-h retention test in pre-exposed subjects given post-training epinephrine $(0.1 \mathrm{mg} / \mathrm{kg})$ relative to saline-treated pre-exposed controls that showed only mild levels of freezing behavior in experiments 1 and 2. Findings from study 3 revealed that pre-exposed subjects given epinephrine post-conditioning exhibited a significantly greater percentage of freezing behavior during tone-only presentations on a 48 -h retention test than did pre-exposed controls. The epinephrine-induced memory enhancement reflected in a higher percentage of freezing behavior was attenuated by interrupting impulse flow between the vagus nerve and the brainstem by blocking postsynaptic glutamate receptors in the NTS. There were no differences in the percentage of CS-induced freezing between controls and the group given epinephrine systemically and the glutamate receptor antagonist $\mathrm{CNQX}$ in the NTS. The overall findings suggest that exposure to a novel context increases physiological arousal, and these changes impact the strength of Pavlovian conditioning by influencing peripheral hormonal systems.

Previous studies demonstrate that several physiological indices of arousal such as heart rate and blood pressure are increased after the initial exposure to a new context (Carrive 2000). For instance, exposure to unfamiliar stimuli, such as water-immersion, handling, or placement into a new cage, results in increased activation of the sympatheticadrenal system that is reflected by elevated concentrations of epinephrine in plasma (De Boer et al. 1990). Research also indicates that these exaggerated hormonal responses to novelty are suppressed by familiarizing subjects to a novel context by either repetitive or prolonged exposure to arousing stimuli (De Boer et al. 1988; Konarska et al. 1989, 1990). Based on these physiological findings, the present studies were conducted to examine the mechanism by which novelty produced physiological arousal impacts memory.

Findings from experiment 1 indicate epinephrine is involved in the capacity for novelty-induced arousal to impact the strength new events are encoded into memory. The level of freezing exhibited by non-pre-exposed animals given the peripheral 
$\beta$-adrenergic receptor antagonist sotalol were comparable to the levels of freezing demonstrated when the CS was presented for saline-injected pre-exposed animals. This view is also supported by studies showing that arousal-induced changes in peripheral autonomic functioning involving elevated heart rate, increased discharge along vagal nerve fibers, and blood pressure are significantly reduced by blocking peripheral $\beta$-adrenergic receptors (van den Buuse et al. 2001; van den Buuse 2002; Carrive 2006; Miyahsita and Williams 2006). The findings from experiment 1 demonstrate arousal states can be regulated by the novelty of stimuli, and novelty-induced arousal affects the formation of memory.

It is important to note that the dose of sotalol selected for the present study did not in itself impair memory for pre-exposed control animals, suggesting this dose of sotalol was low enough to only partially saturate $\beta$-adrenergic receptors (Nattel et al. 1989). The absence of any observable impairment in pre-exposed sotaloltreated subjects may be related to floor effects of freezing performance produced by the mild training footshock. For example, the mild intensity $0.35-\mathrm{mA}$ footshock used in this study was identified as the lowest level of shock intensity that is capable of eliciting cued-conditioned learning (Phillips and LeDoux 1992; Baldi et al. 2004). Therefore, this intensity was utilized to produce mild levels of freezing in controls to better examine whether the arousal produced by novelty improves overall fear conditioned learning in the non-pre-exposed groups. It is plausible that training parameters that produce higher percentages of freezing behavior in controls would, in fact, demonstrate that blocking peripheral $\beta$-adrenergic receptors with sotalol produces learning deficits. However, this type of training regimen will obscure the changes in learning and memory formation produced by novelty-induced increases in arousal.

Numerous studies indicate the adrenal stress hormone epinephrine modulates memory formation for emotional events experienced by humans or animals. These effects are attributed to epinephrine acting directly on peripheral $\beta$-adrenergic receptors (Sternberg et al. 1986; Introini-Collison et al. 1992) and indirectly on NTS and LC neurons to potentiate noradrenergic activation of the amygdala and hippocampus (Williams et al. 1998, 2000; Miyashita and Williams 2004). Experiment 2 examined whether novelty-induced increases in peripheral autonomic and hormonal output affect central mnemonic processing by increasing synaptic transmission between peripheral vagal fibers and the neurons they synapse upon in the NTS. The vagus nerve was targeted as a putative pathway since the peripheral endings of the vagus innervate a broad spectrum of sensory organs that show heightened activity in response to epinephrine secretion (Shapiro and Miselis 1985; Coupland et al. 1989; Paton 1998a, b), and systemic administration of epinephrine increases neural impulses propagated along the vagus nerve as well as the firing rates in NTS neurons (Papas et al. 1990; Miyashita and Williams 2006). These findings suggest that the vagus nerve is capable of relaying peripheral physiological changes following the secretion of epinephrine to the brain in response to highly arousing experiences.

The amino acid glutamate is the primary neurotransmitter to mediate synaptic communication between vagal afferents and neurons they synapse upon in the brain stem. For example, direct stimulation of ascending vagal fibers causes a significant increase in glutamate concentrations measured in the NTS (Granata and Reis 1983b; Allchin et al. 1994). Consistent with these findings, experiment 2 showed that blocking glutamate receptors in the NTS with the antagonist CNQX attenuates the memory improvement observed by conditioning animals in an unfamiliar context. The dose of CNQX used to block AMPA receptors in the NTS was selected specifically from those previously shown to suppress NTS neuronal firing in response to stimulation of the vagus nerve (Granata and Reis 1983a; Andresen and Yang 1990). Findings from this experiment demonstrated that novelty-induced arousal enhancement in memory is attenuated when synaptic communication between vagal afferents and brainstem neurons in the NTS are interrupted.

Arousal-induced increases in autonomic activity that are conveyed to the brain by the vagus nerve play an important role in producing functional and structural changes in brainstem neurons that are conducive to learning. For example, synaptic modifications increasing the efficiency of glutamatergic signaling in the NTS, such as increases in AMPA receptor subunit expression and structural changes at the synapse, occur from increased and sustained ascending peripheral signals such as hypertension and vagus nerve stimulation (for review, see Kline 2008). Furthermore, selective breeds with heightened states of autonomic activity such as spontaneously hypertensive rats show a number of synaptic modifications in the NTS such as a greater number of dendritic spines, an increase in the proportion of those spines that contain the GluR1 subunit of AMPA receptors, and an increase in the total AMPA receptor mRNA expression within the NTS compared with normotensive rats (Aicher et al. 2003; Saha et al. 2004; Hermes et al. 2008). Likewise, brief changes in blood pressure comparable to acute episodes of heightened arousal from an emotional event induce structural changes in neurons that indicate increased transcription at glutamatergic synapses in the NTS. As such, the collective findings suggest that highly arousing experiences that produce structural adaptations in the NTS through the release of glutamate may represent one mechanism by which emotional events are initially encoded and later processed by other limbic structures into long tern memory.

Several behavioral studies demonstrate increased glutamate transmission in the NTS enhances memory for emotionally arousing experiences. For instance, microinjecting glutamate into the NTS where its neurons synapse with vagal afferents improves memory for the context where laboratory animals were last shocked in a water-motivated inhibitory avoidance task (Miyashita and Williams 2002; Kerfoot et al. 2008). The present study demonstrated that antagonizing glutamatergic transmission in the NTS with the selective AMPA receptor antagonist CNQX blocks the memory enhancing effects of heightened arousal from nonpre-exposure to the conditioning chamber. This study extends our understanding of the consequences of arousal on cognitive processes by revealing that postsynaptic AMPA receptors in the NTS transmit the physiological changes from novelty-induced arousal that enhance cued-fear conditioned memory.

Overall, findings from experiments 1 and 2 suggest noveltyinduced arousal affects mnemonic processes by influencing peripheral hormone release and subsequent activation of the vagal/ NTS complex. The final experiment was conducted to directly address interactions between peripheral hormones that are released following novelty-induced arousal and their impact on NTS neurons in the brain stem that are sensitive to fluctuations in peripheral autonomic functioning. To this end pre-exposed (nonaroused) animals were trained in the Pavlovian fear conditioning task with procedures identical to that employed in experiments 1 and 2 with the exception that separate groups received postconditioning injections of saline or epinephrine. Findings from experiment 3 suggest that memory enhancement observed in response to novelty-induced arousal may involve peripheral hormonal secretion. This study demonstrated that increasing peripheral sympathetic output with epinephrine injections significantly enhanced the marginal levels of fear conditioning normally observed in groups pre-exposed to the conditioning chamber through habituation. Changes in physiological arousal produced by epinephrine in pre-exposed animals resulted in very high rates of freezing to the CS that were quite similar to that observed in non-pre-exposed animals tested in experiments 1 and 
2. In addition, when physiological arousal is increased by handling following cued fear conditioning (Hui et al. 2006), administering epinephrine or corticosterone after learning tasks such as object recognition (Roozendaal et al. 2006; Dornelles et al. 2007), viewing a series of neutral slides (Cahill and Alkire 2003), or receiving a footshock in a distinct context (Introini-Collison and McGaugh 1988), memory for the CS, the location of objects, slides viewed, or the context where given a footshock is improved. The findings from experiment 3 further suggest heightened states of arousal impact memory. Moreover, this study demonstrates that peripheral epinephrine is involved in the novelty-induced arousal memory enhancement in that it requires the same glutamatergic mechanism in the NTS. Given the mounting evidence that novelty and peripheral adrenergic mechanisms work in concert to strengthen synaptic connections, the current findings underscore the importance of signaling between the vagus and NTS complex in mediating the beneficial consequences of emotional arousal on memory.

\section{Materials and Methods}

\section{Subjects}

Eighty-three male Sprague-Dawley rats (275-300 g) obtained from Charles River Laboratories (Wilmington, MA) were used in experiments $1(n=24), 2(n=29)$, and $3(n=30)$. Rats were individually housed in plastic cages and maintained on a standard 12:12-h light-dark cycle with lights on at 7:00 a.m. Food and water were available ad libitum during the 7-d undisturbed adaptation period to the vivarium. All experiments were conducted in accordance to the policies and guidelines of the University of Virginia's Animal Care and Use Committee.

\section{Surgery}

Each rat received an injection of atropine sulfate $(0.1 \mathrm{mg} / \mathrm{kg}$, i.p., American Pharmaceutical Partners, Inc.) followed 10 min later by an injection of the anesthetic sodium pentobarbital $(50 \mathrm{mg} / \mathrm{kg}$, i.p., Abbot Laboratories). A midline scalp incision was made, and 15-mm-long, extra-thin-wall stainless steel guide cannulae $(25.0$ gauge, Small Parts) were implanted bilaterally $2 \mathrm{~mm}$ above the NTS (AP: -13.3 ; ML: \pm 1.0 from bregma; DV: -5.6 from the skull surface) according to coordinates adapted from the atlas of Paxinos and Watson (1986). Guide cannulae and skull screws were anchored to the skull with dental cement, and the scalp was closed with sutures. Stylets $(15 \mathrm{~mm}, 00$ insect dissection pins) were inserted into the injection cannulae to maintain cannula patency. Penicillin (0.1 mL, i.m., Fort Dodge Animal Health) was administered immediately after surgery along with the analgesic buprenex (0.05 mL s.c., Hospira, Inc.) to alleviate postsurgical discomfort. The rats remained in a temperature-controlled chamber for at least $1 \mathrm{~h}$ following surgery and were given $7 \mathrm{~d}$ to recover before the start of each study.

\section{Microinjection procedure}

Each rat was restrained by hand in the experimenter's lap, stylets were removed, and 17-mm-long, 30-gauge injection needles were inserted bilaterally into the NTS guide cannulae. The tip of the injection needle extended $2 \mathrm{~mm}$ beyond the base of the guide cannulae. The needles were connected to $10-\mu \mathrm{L}$ Hamilton syringes via PE-20 (polyethylene) tubing. An automated syringe pump (Sage-Orion) delivered $0.5 \mu \mathrm{L}$ of PBS or the AMPA receptor antagonist CNQX (1.0 $\mu \mathrm{g}$; Sigma Aldrich) into the NTS over a period of $60 \mathrm{sec}$. The dose of CNQX used in this study was selected from a range of doses that effectively reduce NTS neural activity (Andresen and Yang 1990). The injection needles were retained in the guide cannulae for an additional $60 \mathrm{sec}$ following infusions to ensure complete delivery of drugs. The stylets were then reinserted into the cannulae, and each rat received an i.p. injection of either saline or epinephrine $(0.1 \mathrm{mg} / \mathrm{kg})$.

\section{Systemic injections}

Subjects in the first experiment received preconditioning systemic (i.p.) injections of saline or sotalol $(4 \mathrm{mg} / \mathrm{kg}), 5 \mathrm{~min}$ before placement into the conditioning chambers.

\section{Behavioral apparatus}

The apparatus used for Pavlovian fear conditioning consisted of a Coulbourn behavioral chamber $(12$ inches width $\times 10$ inches depth $\times 12$ inches height, model no. H13-16) that was enclosed in a larger sound-attenuating box (28 inches width $\times 16$ inches depth $\times 16$ inches height). The front and back walls of the chamber were made of clear plastic with stainless steel sides and a removable stainless steel grid floor. Freezing behavior was recorded during behavioral testing with an infrared activity monitor (model no. H24-61) that samples movement every 400 msec. The chambers used to assess retention for tone-shock pairings were identical in dimensions to the training apparatus but modified to be contextually different from the conditioning chambers and were located in a different room separate from the laboratory. The conditioning chambers were cleaned with a $10 \%$ alcohol solution after training and retention testing. All materials for the behavioral test apparatus were obtained from Coulbourn Instruments.

\section{Behavioral procedures}

\section{Fear conditioning}

Rats were transported from the vivarium into the laboratory $1 \mathrm{~h}$ before behavioral testing. One day prior to conditioning, the rats were habituated to the conditioning chamber with $5 \mathrm{~min}$ of free exploration. Animals assigned to the non-pre-exposure condition were also transported to the laboratory but remained in their home cage during the period that the pre-exposed group was habituated to the conditioning chamber. Twenty-four hours later animals in the pre-exposed or non-pre-exposed groups were placed into the chamber for conditioning. Three minutes after the rats were in the context, a $30-\mathrm{sec}$ tone $(5 \mathrm{kHz}, 75 \mathrm{db}) \mathrm{CS}$ was presented and coterminated with a 1 -sec, $0.35-\mathrm{mA}$ footshock US. A 60 -sec intertrial interval separated the footshock from the presentation of the next tone. Conditioning consisted of five toneshock pairings.

\section{Retention testing}

Animals were transported in pairs to a completely different testing room and behavioral chamber to assess memory for the CS tone 48 $\mathrm{h}$ following conditioning. Each animal was given an initial 3-min period of exploration in the new chamber. Afterward, a CS tone (5 $\mathrm{kHz}, 75 \mathrm{db}$ ) was presented for $30 \mathrm{sec}$ in the absence of the US footshock. A 30-sec intertrial interval separated the end of one tone and the presentation of the next. Three presentations of the CS tone were given during the retention test. The percentage of time subjects displayed a freezing response during presentation of the CS tone that was previously paired with footshocks was used as an index of retention.

\section{Statistical analysis}

Behavioral measures from the fear conditioning task are expressed as the mean percentage of time \pm SE rats spent immobile during the presentation of the tone. Between-group comparisons for the freezing behavior measured during retention testing were made with a two-way ANOVA followed by Fisher's post-hoc tests. Differences less than $P<0.05$ were considered statistically significant.

\section{Histology}

To verify correct placement of injection needle tips and guide cannulae in the NTS after the completion of the experiment, each animal was anesthetized with the euthanasia solution Euthasol $(0.5 \mathrm{~mL}$, Virbac Corporation) and perfused intracardially with $0.9 \%$ saline followed by $10 \%$ formalin. The brains were stored in 
$10 \%$ formalin until sectioned on a vibratome. Sections were cut $60 \mu \mathrm{m}$ thick, mounted on glass slides, subbed with chromiumaluminum, and stained with cresyl violet. The locations of the cannulae and injection needle tips were verified by examining enlarged projections of the slides (Fig. 1). The data from five animals were excluded from statistical analysis because of incorrect cannula placement.

\section{Acknowledgments}

We thank the American Psychological Association Diversity Program in Neuroscience for their predoctoral support. Additionally, we thank Erica J. Young, Erin C. Kerfoot, and Sumi Park for their invaluable contributions. Research was supported by the National Science Foundation (NSF-0720170 to C.L.W.).

\section{References}

Aicher SA, Sharma S, Pickel VM. 1999. N-methyl-D-aspartate receptors are present in vagal afferents and their dendritic targets in the nucleus tractus solitarius. Neuroscience 91: 119-132.

Aicher SA, Sharma S, Mitchell JL. 2002. Co-localization of AMPA receptor subunits in the nucleus of the solitary tract in the rat. Brain Res 958: 454-458.

Aicher SA, Sharma S, Mitchell JL. 2003. Structural changes in AMPA-receptive neurons in the nucleus of the solitary tract of spontaneously hypertensive rats. Hypertension 41: 1246-1252.

Akirav I, Richter-Levin G. 1999. Biphasic modulation of hippocampal plasticity by behavioral stress and basolateral amygdala stimulation in the rat. J Neurosci 19: 10530-10535.

Alberini CM. 2009. Transcription factors in long-term memory and synaptic plasticity. Physiol Rev 89: 121-145.

Allchin R, Batten T, McWilliam P, Vaughan P. 1994. Electrical stimulation of the vagus increases extracellular glutamate recovered from the nucleus tractus solitarii of the cat by in vivo microdialysis. Exp Physiol 79: 265-268

Andresen MC, Yang MY. 1990. Non-NMDA receptors mediate sensory afferent synaptic transmission in medial nucleus tractus solitarius. Am I Physiol 259: 1307-1311.

Baldi E, Lorenzini CA, Bucherelli C. 2004. Footshock intensity and generalization in contextual and auditory-cued fear conditioning in the rat. Neurobiol Learn Mem 81: 162-166.

Bradley MM, Lang PJ, Cuthbert BN. 1993. Emotion, novelty, and the startle reflex: Habituation in humans. Behav Neurosci 107: 970-980.

Cahill L, Alkire MT. 2003. Epinephrine enhancement of human memory consolidation: Interaction with arousal at encoding. Neurobiol Learn Mem 79: 194-198.

Cahill L, Prins B, Weber M, McGaugh JL. 1994. $\beta$-Adrenergic activation and memory for emotional events. Nature 371: 702-704.

Carrive P. 2000. Conditioned fear to environmental context: Cardiovascular and behavioral components in the rat. Brain Res 858: 440-445.

Carrive P. 2006. Dual activation of cardiac sympathetic and parasympathetic components during conditioned fear to context in the rat. Clin Exp Pharmacol Physiol 33: 1251-1254.

Clayton EC, Williams CL. 2000. Noradrenergic receptor blockade of the NTS attenuates the mnemonic effects of epinephrine in an appetitive light-dark discrimination learning task. Neurobiol Learn Mem 74: $135-145$.

Codispoti M, Ferrari V, Bradley MM. 2006. Repetitive picture processing: Autonomic and cortical correlates. Brain Res 1068: 213-220.

Coupland RE, Parker TL, Kesse WK, Mohamed AA. 1989. The innervation of the adrenal gland. III. Vagal innervation. J Anat 163: 173-181.

Davis CD, Jones FL, Derrick BE. 2004. Novel environments enhance the induction and maintenance of long-term potentiation in the dentate gyrus. J Neurosci 24: 6497-6506.

De Boer SF, Slangen JL, van der Gugten J. 1988. Adaptation of plasma catecholamine and corticosterone responses to short-term repeated noise stress in rats. Physiol Behav 44: 273-280.

De Boer SF, Koopmans SJ, Slangen JL, Van der Gugten J. 1990. Plasma catecholamine, corticosterone and glucose responses to repeated stress in rats: Effect of interstressor interval length. Physiol Behav 47: 1117-1124.

Diamond DM, Park CR. 2000. Predator exposure produces retrograde amnesia and blocks synaptic plasticity. Progress toward understanding how the hippocampus is affected by stress. Ann N Y Acad Sci 911: $453-455$.

Diamond DM, Bennett MC, Stevens KE, Wilson RL, Rose GM. 1990. Exposure to a novel environment interferes with the induction of hippocampal primed burst potentiation in the behaving rat. Psychobiology 18: 273-281.

Diamond DM, Fleshner M, Rose GM. 1994. Psychological stress repeatedly blocks hippocampal primed burst potentiation in behaving rats. Behav Brain Res 62: 1-9.

Dornelles A, de Lima MN, Grazziotin M, Presti-Torres J, Garcia VA, Scalco FS Roesler R, Schröder N. 2007. Adrenergic enhancement of consolidation of object recognition memory. Neurobiol Learn Mem 88: 137-142.

Dorr AE, Debonnel G. 2006. Effect of vagus nerve stimulation on serotonergic and noradrenergic transmission. J Pharmacol Exp Ther 318: 890-898.

Fenker DB, Frey JU, Schuetze H, Heipertz D, Heinze HJ, Duzel E. 2008. Novel scenes improve recollection and recall of words. J Cogn Neurosci 20: $1-16$.

Florin-Lechner SM, Druhan JP, Aston-Jones G, Valentino RJ. 1996. Enhanced norepinephrine release in prefrontal cortex with burst stimulation of the locus coeruleus. Brain Res 742: 89-97.

Frankland PW, Josselyn SA, Anagnostaras SG, Kogan JH, Takahashi E, Silva AJ. 2004. Consolidation of CS and US representations in associative fear conditioning. Hippocampus 14: 557-569.

Gerra G, Fertomani G, Zaimovic A, Caccavari R, Reali N, Maestri D, Avanzini P, Monica C, Delsignore R, Brambilla F. 1996. Neuroendocrine responses to emotional arousal in normal women. Neuropsychobiology 33: $173-181$.

Granata AR, Reis DJ. 1983a. Blockade by glutamic acid diethyl ester of excitation of nucleus tractus solitarii neurons and vasodepressor responses reflexly elicited by vagal stimulation. Eur J Pharmacol 89: 95-102.

Granata AR, Reis DJ. 1983b. Release of [ $\left.{ }^{3} \mathrm{H}\right] \mathrm{L}$-glutamine acid (L-glu) and $\left[{ }^{3} \mathrm{H}\right] \mathrm{D}$-aspartic acid (D-asp) in the area of nucleus tractus solitarius in vivo produced by stimulation of the vagus nerve. Brain Res 259: 77-93.

Groves DA, Bowman EM, Brown VJ. 2005. Recordings from the rat locus coeruleus during acute vagal nerve stimulation in the anaesthetized rat. Neurosci Lett 379: 174-179.

Handa RJ, Nunley KM, Lorens SA, Louie JP, McGivern RF, Bollnow MR. 1994. Androgen regulation of adrenocorticotropin and corticosterone secretion in the male rat following novelty and foot shock stressors. Physiol Behav 55: 117-124.

Hassert DL, Miyashita T, Williams CL. 2004. The effects of peripheral vagal nerve stimulation at a memory-modulating intensity on norepinephrine output in the basolateral amygdala. Behav Neurosci 118: 79-88.

Hermes SA, Mitchell JL, Silverman MB, Lynch PJ, McKee BL, Bailey TW, Andresen MC, Aicher SA. 2008. Sustained hypertension increases the density of AMPA receptor subunit, GluR1, in baroreceptive regions of the nucleus tractus solitarii of the rat. Brain Res 1187: 125-136.

Holdefer RN, Jensen RA. 1987. The effects of peripheral D-amphetamine, 4-OH amphetamine, and epinephrine on maintained discharge in the locus coeruleus with reference to the modulation of learning and memory by these substances. Brain Res 417: 108-117.

Hui IR, Hui GK, Roozendaal B, McGaugh JL, Weinberger NM. 2006. Posttraining handling facilitates memory for auditory-cue fear conditioning in rats. Neurobiol Learn Mem 86: 160-163.

Introini-Collison I, McGaugh JL. 1988. Modulation of memory by posttraining epinephrine: Involvement of cholinergic mechanisms. Psychopharmacology 94: 379-385.

Introini-Collison I, Saghafi D, Novack GD, McGaugh JL. 1992. Memory enhancing effects of post-training dipivefrin and epinephrine: Involvement of peripheral and central adrenergic receptors. Brain Res 572: $81-86$.

Izquierdo LA, Barros DM, Medina JH, Izquierdo I. 2000. Novelty enhances retrieval of one-trial avoidance learning in rats 1 or 31 days after training unless the hippocampus is inactivated by different receptor antagonists and enzyme inhibitors. Behav Brain Res 117: 215-220.

Izquierdo LA, Viola H, Barros DM, Alonso M, Vianna MR, Furman M, Levi de Stein M, Szapiro G, Rodrigues C, Choi H, et al. 2001. Novelty enhances retrieval: Molecular mechanisms involved in rat hippocampus. Eur J Neurosci 13: 1464-1467.

Izquierdo LA, Barros DM, Medina JH, Izquierdo I. 2003. Exposure to novelty enhances retrieval of very remote memory in rats. Neurobiol Learn Mem 79: $51-56$.

Kalia M, Sullivan JM. 1982. Brainstem projections of sensory and motor components of the vagus nerve in the rat. J Comp Neurol 211: 248-265.

Kerfoot EC, Chattillion EA, Williams CL. 2008. Functional interactions between the nucleus tractus solitarius (NTS) and nucleus accumbens shell in modulating memory for arousing experiences. Neurobiol Learn Mem 89: 47-60.

Kim JJ, Jung MW. 2006. Neural circuits and mechanisms involved in Pavlovian fear conditioning: A critical review. Neurosci Biobehav Rev 30: 188-202.

Kinney W, Routtenberg A. 1993. Brief exposure to a novel environment enhances binding of hippocampal transcription factors to their DNA recognition elements. Brain Res Mol Brain Res 20: 147-152. 
Kline DD. 2008. Plasticity in glutamatergic NTS neurotransmission. Respir Physiol Neurobiol 164: 105-111.

Konarska M, Stewart RE, McCarty R. 1989. Habituation of sympathetic-adrenal medullary responses following exposure to chronic intermittent stress. Physiol Behav 45: 255-261.

Konarska M, Stewart RE, McCarty R. 1990. Habituation and sensitization of plasma catecholamine responses to chronic intermittent stress: Effects of stressor intensity. Physiol Behav 47: 647-652.

Korol DL, Gold PE. 2008. Epinephrine converts long-term potentiation from transient to durable form in awake rats. Hippocampus 18: 81-91.

Lawrence AJ, Watkins D, Jarrott B. 1995. Visualization of $\beta$-adrenoceptor binding sites on human inferior vagal ganglia and their axonal transport along the rat vagus nerve. J Hypertens 13: 631-635.

Li S, Cullen WK, Anwyl R, Rowan MJ. 2003. Dopamine-dependent facilitation of LTP induction in hippocampal CA1 by exposure to spatial novelty. Nat Neurosci 6: 526-531.

Loughlin SE, Foote SL, Bloom FE. 1986. Efferent projections of nucleus locus coeruleus: Topographic organization of cells of origin demonstrated by three-dimensional reconstruction. Neuroscience 18: 291-306.

McQuade R, Creton D, Stanford SC. 1999. Effect of novel environmental stimuli on rat behaviour and central noradrenaline function measured by in vivo microdialysis. Psychopharmacology 145: 393-400.

Miyashita T, Williams CL. 2002. Glutamatergic transmission in the nucleus of the solitary tract modulates memory through influences on amygdala noradrenergic systems. Behav Neurosci 116: 13-21.

Miyashita T, Williams CL. 2004. Peripheral arousal-related hormones modulate norepinephrine release in the hippocampus via influences on brainstem nuclei. Behav Brain Res 153: 87-95.

Miyashita T, Williams CL. 2006. Epinephrine administration increases neural impulses propagated along the vagus nerve: Role of peripheral $\beta$-adrenergic receptors. Neurobiol Learn Mem 85: 116-124.

Moncada D, Viola H. 2007. Induction of long-term memory by exposure to novelty requires protein synthesis: Evidence for a behavioral tagging. $J$ Neurosci 27: 7476-7481.

Nattel S, Feder-Elituv R, Matthews C, Nayebpour M, Talajic M. 1989. Concentration dependence of class III and $\beta$-adrenergic blocking effects of sotalol in anesthetized dogs. J Am Coll Cardiol 13: 1190-1194.

Nordby T, Torras-Garcia M, Portell-Cortes I, Costa-Miserachs D. 2006. Posttraining epinephrine treatment reduces the need for extensive training. Physiol Behav 89: 718-723.

Papa M, Pellicano MP, Welzl H, Sadile AG. 1993. Distributed changes in c-Fos and c-Jun immunoreactivity in the rat brain associated with arousal and habituation to novelty. Brain Res Bull 32: 509-515.

Papas S, Smith P, Ferguson AV. 1990. Electrophysiological evidence that systemic angiotensin influences rat area postrema neurons. Am J Physiol 258: $70-76$.

Paton JF. 1998a. Convergence properties of solitary tract neurones driven synaptically by cardiac vagal afferents in the mouse. J Physiol 508: 237-252.

Paton JF. 1998b. Importance of neurokinin-1 receptors in the nucleus tractus solitarii of mice for the integration of cardiac vagal inputs. Eur J Neurosci 10: 2261-2275.

Paxinos G, Watson C. 1986. The rat brain in stereotaxic coordinates, 2nd ed. Academic Press, New York.

Phillips RG, LeDoux JE. 1992. Differential contribution of amygdala and hippocampus to cued and contextual fear conditioning. Behav Neurosci 106: $274-285$

Ricardo JA, Koh ET. 1978. Anatomical evidence of direct projections from the nucleus of the solitary tract to the hypothalamus, amygdala, and other forebrain structures in the rat. Brain Res 153: 1-26.

Roozendaal B, Okuda S, Van der Zee EA, McGaugh JL. 2006. Glucocorticoid enhancement of memory requires arousal-induced noradrenergic activation in the basolateral amygdala. Proc Natl Acad Sci 103: 6741-6746.

Saha S, Spary EJ, Maqbool A, Asipu A, Corbett EK, Batten TF. 2004. Increased expression of AMPA receptor subunits in the nucleus of the solitary tract in the spontaneously hypertensive rat. Brain Res Mol Brain Res 121: $37-49$.
Schreurs J, Seelig T, Schulman H. 1986. $\beta_{2}$-Adrenergic receptors on peripheral nerves. J Neurochem 46: 294-296.

Shapiro RE, Miselis RR. 1985. The central organization of the vagus nerve innervating the stomach of the rat. J Comp Neurol 238: 473-488.

Sheth A, Berretta S, Lange N, Eichenbaum H. 2008. The amygdala modulates neuronal activation in the hippocampus in response to spatial novelty. Hippocampus 18: 169-181.

Sierra-Mercado D, Dieguez D Jr, Barea-Rodriguez EJ. 2008. Brief novelty exposure facilitates dentate gyrus LTP in aged rats. Hippocampus 18: 835-843.

Sternberg DB, Korol D, Novack GD, McGaugh JL. 1986. Epinephrineinduced memory facilitation: Attenuation by adrenoceptor antagonists. Eur J Pharmacol 129: 189-193.

Strange BA, Dolan RJ. 2004. $\beta$-Adrenergic modulation of emotional memory evoked human amygdala and hippocampal responses. Proc Natl Acad Sci 101: 11454-11458.

Straube T, Korz V, Balschun D, Frey JU. 2003a. Requirement of $\beta$-adrenergic receptor activation and protein synthesis for LTP-reinforcement by novelty in rat dentate gyrus. J Physiol 552: 953-960.

Straube T, Korz V, Frey JU. 2003b. Bidirectional modulation of long-term potentiation by novelty-exploration in rat dentate gyrus. Neurosci Lett 344: $5-8$.

Sumal KK, Blessing WW, Joh TH, Reis DJ, Pickel VM. 1983. Synaptic interaction of vagal afferents and catecholaminergic neurons in the rat nucleus tractus solitarius. Brain Res 277: 31-40.

Sykes RM, Spyer KM, Izzo PN. 1997. Demonstration of glutamate immunoreactivity in vagal sensory afferents in the nucleus tractus solitarius of the rat. Brain Res 762: 1-11.

Tang AC, Reeb BC. 2004. Neonatal novelty exposure, dynamics of brain asymmetry, and social recognition memory. Dev Psychobiol 44: 84-93.

Van Bockstaele EJ, Peoples J, Telegan P. 1999. Efferent projections of the nucleus of the solitary tract to peri-locus coeruleus dendrites in rat brain: Evidence for a monosynaptic pathway. J Comp Neurol 412: 410-428.

van den Buuse M. 2002. Effect of atropine or atenolol on cardiovascular responses to novelty stress in freely moving rats. Stress 5: 227-231.

van den Buuse M, Van Acker SA, Fluttert M, De Kloet ER. 2001. Blood pressure, heart rate, and behavioral responses to psychological "novelty" stress in freely moving rats. Psychophysiology 38: 490-499.

Vankov A, Hervé-Minvielle A, Sara SJ. 1995. Response to novelty and its rapid habituation in locus coeruleus neurons of the freely exploring rat. Eur J Neurosci 7: 1180-1187.

Viola H, Furman M, Izquierdo LA, Alonso M, Barros DM, de Souza MM, Izquierdo I, Medina JH. 2000. Phosphorylated cAMP response element-binding protein as a molecular marker of memory processing in rat hippocampus: Effect of novelty. J Neurosci 20: 112.

Williams CL, McGaugh JL. 1993. Reversible lesions of the nucleus of the solitary tract attenuate the memory-modulating effects of posttraining epinephrine. Behav Neurosci 107: 955-962.

Williams CL, Men D, Clayton EC, Gold PE. 1998. Norepinephrine release in the amygdala after systemic injection of epinephrine or escapable footshock: Contribution of the nucleus of the solitary tract. Behav Neurosci 112: 1414-1422.

Williams CL, Men D, Clayton EC. 2000. The effects of noradrenergic activation of the nucleus tractus solitarius on memory and in potentiating norepinephrine release in the amygdala. Behav Neurosci 114: 1131-1144.

Xu L, Anwyl R, Rowan MJ. 1997. Behavioural stress facilitates the induction of long-term depression in the hippocampus. Nature 387: 497-500.

Zhu XO, McCabe BJ, Aggleton JP, Brown MW. 1997. Differential activation of the rat hippocampus and perirhinal cortex by novel visual stimuli and a novel environment. Neurosci Lett 229: 141-143.

Received June 16, 2009; accepted in revised form July 31, 2009. 


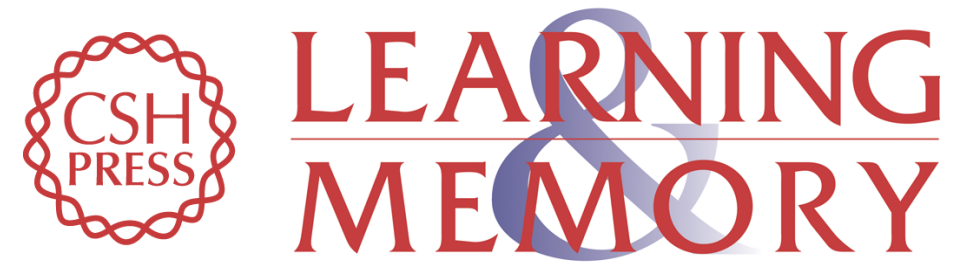

\section{Novelty-induced arousal enhances memory for cued classical fear conditioning: Interactions between peripheral adrenergic and brainstem glutamatergic systems}

Stanley O. King II and Cedric L. Williams

Learn. Mem. 2009, 16:

Access the most recent version at doi:10.1101/lm.1513109

References This article cites 88 articles, 7 of which can be accessed free at: http://learnmem.cshlp.org/content/16/10/625.full.html\#ref-list-1

License

Email Alerting

Receive free email alerts when new articles cite this article - sign up in the box at the Service top right corner of the article or click here. 